\title{
Impaired glucagon-like peptide-1-induced insulin secretion in carriers of transcription factor 7-like 2 (TCF $7 L 2)$ gene polymorphisms
}

\author{
S. A. Schäfer • O. Tschritter • F. Machicao • C. Thamer • \\ N. Stefan • B. Gallwitz • J. J. Holst • J. M. Dekker • \\ L. M. t'Hart • G. Nijpels • T. W. van Haeften • \\ H. U. Häring • A. Fritsche
}

Received: 6 April 2007 / Accepted: 5 June 2007 / Published online: 28 July 2007

(C) Springer-Verlag 2007

\begin{abstract}
Aims/hypothesis Polymorphisms in the transcription factor 7like 2 (TCF7L2) gene are associated with type 2 diabetes and reduced insulin secretion. The transcription factor TCF7L2 is an essential factor for glucagon-like peptide-1 (GLP-1)
\end{abstract}

Electronic supplementary material The online version of this article (doi:10.1007/s00125-007-0753-6) contains supplementary material, which is available to authorised users.

S. A. Schäfer · O. Tschritter $\cdot$ F. Machicao $\cdot$ C. Thamer $\cdot$

N. Stefan • B. Gallwitz $\cdot$ H. U. Häring • A. Fritsche $(\bowtie)$

Division of Endocrinology, Diabetology, Vascular Medicine,

Nephrology and Clinical Chemistry, Department of Internal

Medicine, Eberhard-Karls University of Tübingen,

Otfried-Müller-Str. 10,

72076 Tübingen, Germany

e-mail: andreas.fritsche@med.uni-tuebingen.de

\section{J. J. Holst}

Department of Medical Physiology, Panum Institute,

University of Copenhagen,

Copenhagen, Denmark

J. M. Dekker $\cdot$ G. Nijpels

On behalf of the Hoorn study, EMGO Institute,

Vrije Universiteit Medical Center,

Amsterdam, the Netherlands

L. M. t'Hart

Department of Molecular Cell Biology,

Leiden University Medical Center,

Leiden, the Netherlands

T. W. van Haeften

Department of Internal Medicine,

Utrecht University Medical Center,

Utrecht, the Netherlands secretion from intestinal L cells. We studied whether a defect in the enteroinsular axis contributes to impaired insulin secretion in carriers of TCF7L2 polymorphisms.

Methods We genotyped 1,110 non-diabetic German participants for five single nucleotide polymorphisms in TCF7L2. All participants underwent an OGTT; GLP-1 secretion was measured in 155 participants. In 210 participants, an IVGTT combined with a hyperinsulinaemic-euglycaemic clamp was performed. In another 160 participants from the Netherlands and 73 from Germany, a hyperglycaemic clamp $(10 \mathrm{mmol} / \mathrm{l})$ was performed. In 73 German participants this clamp was combined with a GLP-1 infusion and an arginine bolus.

Results The OGTT data confirmed that variants in TCF7L2 are associated with reduced insulin secretion. In contrast, insulin secretion induced by an i.v. glucose challenge in the IVGTT and hyperglycaemic clamp was not different between the genotypes. GLP-1 concentrations during the OGTT were not influenced by the TCF7L2 variants. However, GLP-1-infusion combined with a hyperglycaemic clamp showed a significant reduction in GLP-1-induced insulin secretion in carriers of the risk allele in two variants (rs7903146, rs12255372, $p<0.02$ ).

Conclusions/interpretation Variants of TCF7L2 specifically impair GLP-1-induced insulin secretion. This seems to be rather the result of a functional defect in the GLP-1 signalling in beta cells than a reduction in GLP-1 secretion. This defect might explain the impaired insulin secretion in carriers of the risk alleles and confers the increased risk of type 2 diabetes.

Keywords GLP-1 Insulin secretion · Polymorphism · TCF7L2 


\section{Abbreviations \\ GLP-1 glucagon-like peptide-1 \\ SNP single nucleotide polymorphism \\ TCF7L2 transcription factor 7-like 2}

\section{Introduction}

Genome-wide scans for diabetes susceptibility genes have been performed in various populations. In early 2006 , it was reported that variants in the transcription factor 7-like 2 (TCF7L2) gene were strongly associated with an increased risk of type 2 diabetes in an Icelandic, a Danish and a US population [1]. The estimated population attributable risk of type 2 diabetes of this variation lies between 10 and $25 \%$, which is in the range of the peroxisome proliferator-activated receptor $\gamma$ gene $(P P A R \gamma)$ Pro12Ala (25\% [2]) and the potassium inwardly-rectifying channel, subfamily $\mathrm{J}$, member 11 gene (KCNJ11) Glu23Lys (15\% [3]) polymorphisms.

In the initial report of Grant et al. [1], five single nucleotide polymorphisms (SNPs) within introns 3 and 4 of the TCF7L2 gene (rs12255372, rs7903146, rs7901695, rs11196205, rs7895340) were identified to associate with an increased risk of type 2 diabetes. This finding initiated a series of reports in various populations confirming the effect of these polymorphisms within the TCF $7 L 2$ gene on the type 2 diabetes risk [4-12]. Recently, the $\mathrm{T}$ allele of rs7903146 was identified as the variant that most strongly determines the risk of type 2 diabetes [13]. In carriers of the risk alleles for SNPs within TCF7L2 several studies additionally showed an impaired insulin secretion estimated from an OGTT or IVGTT $[6,7,9,10]$. These studies indicate that progressive loss of insulin secretion might be the essential component of the phenotype which predisposes carriers of the TCF7L2 variant to develop type 2 diabetes. The pathogenic mechanism of the impaired insulin secretion due to polymorphisms in the TCF7L2 gene is not yet clear. It could be the consequence of a reduction in beta cell mass or could reflect a dysfunction of pancreatic beta cells. Furthermore, a defect in incretin-induced stimulus secretion coupling could mediate a reduction of insulin secretion in carriers of the TCF7L2 polymorphisms. The latter hypothesis is supported by the molecular mode of action of the transcription factor TCF7L2. TCF7L2 is an essential component of the wingless-type MMTV integration site family, member $1(W N T)$ signalling pathway, which is crucial for the regulation of the glucagon gene $(G C G)$ expression and the secretion of its product GLP-1 by the intestinal endocrine L cells [14]. Therefore, an alteration in the WNT signalling pathway through polymorphisms in the TCF7L2 gene might result in an altered GLP-1 response, which in turn could lead to a lower postprandial insulin secretion.
To test this hypothesis we analysed the associations of the above-described TCF7L2 polymorphisms with basal GLP-1 secretion and glucose-induced GLP-1 response during an OGTT in non-diabetic participants. We further studied the influence of the TCF7L2 SNPs on insulin secretion kinetics to i.v. administered glucose during an IVGTT and a hyperglycaemic clamp. In addition, we particularly investigated the influence on GLP-1-induced insulin secretion using a combined hyperglycaemic clamp with additional GLP-1 infusion and arginine bolus [15].

\section{Methods}

Participants We studied 1,110 non-diabetic participants by an OGTT (Table 1). Secretion patterns of GLP-1 were obtained in a subgroup of 155 participants. The anthropometric characteristics of this subgroup are shown in Table 2. All 1,110 participants were also genotyped for the following five SNPs in the TCF7L2 gene: rs7903146, rs12255372, rs7901695, rs11196205 and rs7895340.

A subset of 210 participants were studied by an IVGTT combined with a euglycaemic-hyperinsulinaemic clamp to determine insulin secretion capacity and insulin sensitivity in one test [16] (Table 3).

Additionally, 233 participants were studied by a hyperglycaemic clamp [17]. The participants were selected from three independent studies in the Netherlands and Germany. The German and the Dutch cohort from Utrecht consisted of NGT and IGT participants, the Dutch cohort from Hoorn consisted of IGT participants only (Table 4). All participants in our studies underwent a standard OGTT to define their glucose tolerance status. Details of the study groups have been described previously [17-19]. In the German subgroup $(n=73)$, the hyperglycaemic clamp was continued with an additional GLP-1 and arginine administration [15, 20-22].

The participants were not related to each other. Informed written consent for all studies was obtained from all participants, and the local ethics committee approved the protocols.

Genotyping Detection of the TCF7L2 polymorphisms described by Grant et al. [1] was done using the TaqMan assay (Applied Biosystems, Forster City, CA, USA) in the German population. The TaqMan genotyping reaction was amplified on a GeneAmp PCR system 7000, and fluorescence was detected on an ABI PRISM 7000 sequence detector (Applied Biosystems). As a quality standard, we randomly included six positive (two homozygous wild-type allele carriers, two heterozygous and two homozygous risk allele carriers) and two negative (all components excluding DNA) sequenced controls in each TaqMan reader plate. Because all controls were correctly identified, we assumed 
that the genotyping error rate of this method did not exceed $0.3 \%$ [23].

In the Dutch population, only rs7903146 was determined using an ABI PRISM 7900HT sequence detector (Applied Biosystems).

OGTT At 08:00 hours, participants ingested a solution containing $75 \mathrm{~g}$ glucose. Venous blood samples were obtained at $0,30,60,90$ and $120 \mathrm{~min}$ for determination of plasma glucose, insulin and C-peptide concentrations and 0,30 and $120 \mathrm{~min}$ for determination of GLP-1 concentrations. The participants did not take any medication known to affect glucose tolerance or insulin sensitivity. Tests were performed after an overnight fast of $12 \mathrm{~h}$.

Combined IVGTT and hyperinsulinaemic-euglycaemic clamp After an overnight fast and after baseline samples had been obtained, $0.3 \mathrm{~g} / \mathrm{kg}$ bodyweight of a $20 \%$ (vol./vol.) glucose solution was given at time 0 . Blood samples for the measurement of plasma glucose, plasma insulin and C-peptide were obtained at 2, 4, 6, 8, 10, 20, 30, 40, 50 and $60 \mathrm{~min}$. After $60 \mathrm{~min}$, a priming dose of insulin was given followed by an infusion $\left(40 \mathrm{mU} / \mathrm{m}^{2}\right)$ of short-acting human insulin for $120 \mathrm{~min}$. A variable infusion of $20 \%$ glucose was started to maintain the plasma glucose concentration at $5.5 \mathrm{mmol} / \mathrm{l}$. Blood samples for the measurement of plasma glucose were obtained at $5 \mathrm{~min}$ intervals throughout the clamp.

Hyperglycaemic clamp Hyperglycaemic clamps were performed at $10 \mathrm{mmol} / \mathrm{l}$ in all participants. The Dutch NGT and IGT participants underwent a 3 h clamp. In the German NGT participants, the clamp lasted for $2 \mathrm{~h}$ followed by the GLP-1 and arginine stimulation (see below). After an overnight fast, the participants received an i.v. glucose bolus to acutely raise glucose levels to $10 \mathrm{mmol} / 1$. Plasma glucose levels were measured at the appropriate intervals to maintain a constant plasma glucose during the clamp. Blood samples for insulin were drawn at 2.5 min intervals during the first $10 \mathrm{~min}$ of the clamp and at 10-20 $\mathrm{min}$ intervals during the remainder. Exact details of the clamping procedures in the different study groups have been described previously $[15,18,19]$.

Combined hyperglycaemic clamp This hyperglycaemic clamp combined with GLP-1 and arginine administration was performed as previously described [15, 20-22]. After $120 \mathrm{~min}$ of hyperglycaemic clamp at $10 \mathrm{mmol} / \mathrm{l}$, a bolus of GLP-1 (0.6 pmol/kg) was given (human GLP-1(7-36) amide; Poly Peptide, Wolfenbüttel, Germany) followed by a continuous GLP-1 infusion ( $1.5 \mathrm{pmol} \mathrm{kg}^{-1} \mathrm{~min}^{-1}$ ) during the next $80 \mathrm{~min}$. At $180 \mathrm{~min}$, a bolus of $5 \mathrm{~g}$ arginine hydrochloride (Pharmacia \& Upjohn, Erlangen, Germany) was injected over $45 \mathrm{~s}$ while the GLP-1 infusion was continued. Blood for the measurement of glucose, insulin, proinsulin and C-peptide was obtained during the timepoints shown in Fig. 1. This clamp allows measurement of different aspects of stimulus secretion coupling: first and second phases of glucose-induced insulin secretion, GLP-1induced insulin secretion, and the response to additional arginine administration.

Analytical procedures Plasma glucose was determined as previously described [14, 17, 20, 21]. GLP-1 was determined during the OGTT at baseline, 30 and 120 min. GLP-1 immunoreactivity was determined using an RIA specific for the C-terminus of the peptide [24]. Samples were stored at $-80^{\circ} \mathrm{C}$. The assay measures the sum of the intact peptide plus the primary metabolite, GLP-1(9-36)amide using the polyclonal anti-GLP-1 antibody 89390 and synthetic GLP-1(7-36)amide as standard.

Plasma insulin and C-peptide concentrations in the German cohort were measured by a microparticle enzyme immunoassay (Abbott, Wiesbaden, Germany) and an RIA (Byk-Santec, Dietzenbach, Germany). In the participants from the Netherlands, insulin was measured using an in-house competitive RIA employing a polyclonal anti-insulin antibody (Caris 46), ${ }^{125}$ I-labelled insulin (IM 166; Amersham, Roosdaal, the Netherlands) as a tracer and regular insulin (Humulin; Eli Lilly, Indianapolis, IN, USA) as a standard.

Calculations Insulin secretion in the OGTT was assessed by calculating the AUC for C-peptide divided by the AUC for glucose $\left(\mathrm{AUC}_{\mathrm{CP}} / \mathrm{AUC} \mathrm{Glc}_{\mathrm{Gl}}\right)$. AUCs were determined by the trapezoidal method. Furthermore, insulin secretion was calculated as insulin:glucose ratio by dividing (insulin at $30 \mathrm{~min}-$ insulin at $0 \mathrm{~min}$ ) by (glucose at $30 \mathrm{~min}-$ glucose at $0 \mathrm{~min}$ ). Insulin sensitivity during the OGTT was estimated from glucose and insulin values as proposed by Matsuda and DeFronzo [25].

Insulin secretion during the IVGTT was calculated as the sum of C-peptide levels during the first $10 \mathrm{~min}$ after glucose administration. Insulin sensitivity during the hyperinsulinaemic-euglycaemic clamp was calculated by dividing the average glucose infusion rate during the last 40 min of the clamp by the average plasma insulin concentration during the same time interval.

Insulin secretion during the hyperglycaemic clamp was calculated using insulin levels determined during the clamp. The first phase of insulin secretion was defined as the sum of the insulin levels during the first $10 \mathrm{~min}$ of the clamp. The second phase of insulin secretion was defined as the mean of the insulin values during the last $40 \mathrm{~min}$ (80-120 min, NGT group, Germany) or the last $30 \mathrm{~min}$ (150-180 min, NGT and IGT groups, the Netherlands) of the clamp. 
In the combined hyperglycaemic clamp with GLP-1 and arginine administration, first-phase GLP-1-induced insulin secretion was defined as the mean of the 125 and $130 \mathrm{~min}$ insulin levels, second-phase GLP-induced insulin secretion (plateau) was defined as the mean of the 160-180 min insulin levels. The acute insulin response to arginine was calculated as the mean of 182.5 and 185 min minus $180 \mathrm{~min}$ insulin levels [21].

The insulin sensitivity index was determined by relating the glucose infusion rate to the plasma insulin concentration during the last $40 \mathrm{~min}$ (NGT, Germany) or $30 \mathrm{~min}$ of the clamp.

Statistical analysis Data are given as means \pm SEM. Nonnormally distributed parameters were logarithmically transformed to approximate linearity for statistical comparison. Distribution was tested for normality using the ShapiroWilk $W$ test. Differences in anthropometrics and metabolic characteristics between genotypes were tested using ANOVA for the three genotype groups. The secretion indices were compared using multivariate regression models. In these models the trait was the dependent variable whereas age, sex, insulin sensitivity and genotype were the independent variables. Due to the relatively low number of participants who were homozygous for the rare alleles in the hyperglycaemic clamp group, a dominant model was used. A $p$ value of $<0.05$ was considered to be statistically significant. The statistical software package JMP (SAS Institute, Cary, NC, USA) was used.

\section{Results}

Genetic variants in the TCF7L2 gene The SNPs described in the paper of Grant et al. [1] had an allelic frequency of the minor allele of $30 \%$ (rs7903146), 28\% (rs12255372), $31 \%$ (rs7901695), 46\% (rs11196205) and 45\% (rs7895340) in our population. These polymorphisms were all in Hardy-Weinberg equilibrium and in linkage disequilibrium (Electronic supplementary material Table 1).

OGTT: glucose tolerance, insulin secretion, insulin sensitivity and GLP-1 levels The percentage of participants with IGT was significantly higher in carriers of the risk allele for rs7903146 $(p=0.007), \operatorname{rs} 12255372(p=0.02)$ and rs7901695 $(p=0.02)$.

Insulin secretion assessed as $\mathrm{AUC}_{\mathrm{CP}} / \mathrm{AUC}_{\mathrm{Glc}}$ during the OGTT was significantly reduced in participants with the risk alleles for rs7903146 and rs12255372 in the additive and dominant model both unadjusted and adjusted for relevant covariates. Participants with the risk allele for rs7901695 had a significantly decreased insulin secretion in the additive model $(p=0.02)$ (Table 1).

Insulin sensitivity, estimated by the index of Matsuda and DeFronzo [25], was significantly higher in participants carrying the risk alleles for rs7903146 and rs1255372 in TCF7L2 (Table 1).

In a subgroup of 155 participants we measured GLP-1 concentrations at baseline, at $30 \mathrm{~min}$ and $120 \mathrm{~min}$ after oral ingestion of $75 \mathrm{~g}$ glucose. The anthropometric characteristics are shown in (Table 1). Neither basal GLP-1 plasma levels nor GLP-1 levels during the OGTT significantly differed between the genotypes in any of the above-described SNPs in the TCF7L2 gene (Table 2).

Combined IVGTT and hyperinsulinaemic-euglycaemic clamp: glucose-induced insulin secretion and insulin sensitivity C-peptide and insulin values during the IVGTT were not significantly different between the genotypes in any of the above-described SNPs in the TCF7L2 gene. Table 3 shows the results for rs 7903146 in the additive and dominant model adjusted for relevant covariates. Including the glucose tolerance status as an additional co-variate in the model did not affect the results. Interestingly, a lower insulin secretion in this subgroup of participants could be demonstrated when insulin secretion was calculated from the OGTT as described above (Table 3). Insulin sensitivity measured with the clamp technique was not affected by any of the genotypes (all $p>0.4$ ).

Hyperglycaemic clamp: glucose-, GLP-1- and arginineinduced insulin secretion and insulin sensitivity First- and second-phase insulin secretion during the hyperglycaemic clamp were not significantly different between carriers and non-carriers of the risk allele for rs7903146 (Table 4) in any of the three populations from the Netherlands and from Germany. The other four SNPs in TCF7L2 which were described above were determined in the German population only and were not associated with glucoseinduced insulin secretion (data not shown) during the hyperglycaemic clamp.

The first phase of GLP-1-induced insulin secretion was significantly reduced in carriers of the risk alleles for rs7903146 $(p=0.03)$ and $r 12255372(p=0.02)$. In addition, we found significant differences in the second phase of GLP-1-induced insulin secretion for rs7903146 ( $p=$ $0.006)$, rs $12255372(p=0.005)$ and $\operatorname{rs} 7901695(p=0.02)$ with carriers of the risk alleles having a significantly lower second phase of GLP-1-induced insulin secretion. Table 4 and Fig. 1 show the results for SNP rs7903146.

In contrast to GLP-1-induced insulin secretion, arginine-induced insulin secretion was not affected by any of the analysed SNPs in TCF7L2 (Table 4). 
Table 1 Anthropometric and metabolic data from all 1,110 participants who underwent an OGTT

\begin{tabular}{|c|c|c|c|c|c|}
\hline \multirow[b]{2}{*}{ Genotype } & \multicolumn{3}{|l|}{ rs7903146 } & \multirow[t]{2}{*}{$p$ value (ANOVA) } & \multirow[t]{2}{*}{$p$ value (CC vs XT) } \\
\hline & $\mathrm{C} / \mathrm{C}$ & $\mathrm{C} / \mathrm{T}$ & $\mathrm{T} / \mathrm{T}$ & & \\
\hline$n$ & 546 & 474 & 90 & & \\
\hline NGT/IGT & $461 / 85$ & $386 / 88$ & $63 / 27$ & 0.007 & 0.03 \\
\hline Sex (female/male) & $346 / 200$ & $315 / 159$ & $50 / 40$ & 0.13 & 0.64 \\
\hline Age (years) & $39 \pm 1$ & $40 \pm 1$ & $41 \pm 1$ & 0.39 & 0.67 \\
\hline BMI $\left(\mathrm{kg} / \mathrm{m}^{2}\right)$ & $29.5 \pm 0.4$ & $28.9 \pm 0.4$ & $28.2 \pm 1.0$ & 0.51 & 0.24 \\
\hline \multicolumn{6}{|l|}{ Plasma glucose $(\mathrm{mmol} / \mathrm{l})$} \\
\hline Fasting & $5.1 \pm 0.02$ & $5.1 \pm 0.02$ & $5.2 \pm 0.07$ & 0.25 & 0.39 \\
\hline $2 \mathrm{~h}$ & $6.1 \pm 0.07$ & $6.2 \pm 0.07$ & $6.7 \pm 0.2$ & 0.06 & 0.17 \\
\hline \multicolumn{6}{|l|}{ Plasma insulin (pmol/l) } \\
\hline Fasting & $62.0 \pm 2.1$ & $53.4 \pm 1.7$ & $49.8 \pm 3.1$ & 0.004 & 0.001 \\
\hline $2 \mathrm{~h}$ & $442 \pm 19$ & $356 \pm 17$ & $372 \pm 34$ & 0.12 & 0.04 \\
\hline Insulin sensitivity ${ }_{\text {OGTT }}$ (arbitrary units) & $16.8 \pm 0.5$ & $18.2 \pm 0.5$ & $17.8 \pm 1.2$ & $0.02 / 0.02^{\mathrm{a}}$ & $0.005 / 0.006^{\mathrm{a}}$ \\
\hline Insulin secretion ${ }_{\text {OGTT }}(\mathrm{pmol} / \mathrm{mmol})$ & $319 \pm 5$ & $301 \pm 5$ & $292 \pm 10$ & $0.003 / 0.04^{\mathrm{b}}$ & $0.0009 / 0.02^{\mathrm{b}}$ \\
\hline Insulin/glucose ratio (pmol/mmol) & $143 \pm 5$ & $127 \pm 5$ & $124 \pm 13$ & $0.003 / 0.03^{\mathrm{b}}$ & $0.001 / 0.01^{\mathrm{b}}$ \\
\hline
\end{tabular}

Data are means \pm SEM

$p$ values were obtained using $\chi^{2}$ test or ANOVA

Analysis for rs 12255372 and rs7901695 also revealed a significant difference in insulin secretion ( $p=0.003$ and $p=0.05)$, whereas for rs7895340 and rs11196205 no significant differences in insulin secretion were detected ( $p=0.53$ and 0.45$)$

${ }^{a} p$ values are derived from multivariate linear regression models: adjusted for age, sex and BMI

${ }^{\mathrm{b}} p$ values are derived from multivariate linear regression models: adjusted for age, sex, BMI and insulin sensitivity

Table 2 Anthropometric and metabolic data of the subgroup of 155 participants with additional measurements of GLP-1

\begin{tabular}{|c|c|c|c|c|c|}
\hline \multirow[b]{2}{*}{ Genotype } & \multicolumn{3}{|l|}{ rs7903146 } & \multirow[t]{2}{*}{$p$ value (ANOVA) } & \multirow[t]{2}{*}{$p$ value $(\mathrm{CC}$ vs $\mathrm{XT})$} \\
\hline & $\mathrm{C} / \mathrm{C}$ & $\mathrm{C} / \mathrm{T}$ & $\mathrm{T} / \mathrm{T}$ & & \\
\hline$n$ & 73 & 67 & 15 & & \\
\hline NGT/IGT & $64 / 9$ & $48 / 19$ & $10 / 5$ & 0.03 & 0.009 \\
\hline Sex (female/male) & $50 / 23$ & $42 / 25$ & $8 / 7$ & 0.50 & 0.33 \\
\hline Age (years) & $46 \pm 1$ & $47 \pm 1$ & $47 \pm 3$ & 0.99 & 0.96 \\
\hline BMI $\left(\mathrm{kg} / \mathrm{m}^{2}\right)$ & $29.8 \pm 0.7$ & $30.3 \pm 0.7$ & $27.1 \pm 1.1$ & 0.15 & 0.88 \\
\hline \multicolumn{6}{|l|}{ Plasma glucose $(\mathrm{mmol} / \mathrm{l})$} \\
\hline Fasting & $5.2 \pm 0.05$ & $5.3 \pm 0.07$ & $5.6 \pm 0.2$ & 0.17 & 0.21 \\
\hline $2 \mathrm{~h}$ & $6.5 \pm 0.1$ & $7.0 \pm 0.2$ & $7.2 \pm 0.5$ & 0.22 & 0.10 \\
\hline Insulin sensitivity ${ }_{\text {OGTT }}$ (arbitrary units) & $12.8 \pm 0.7$ & $13.6 \pm 1.0$ & $15.7 \pm 2.6$ & $0.74 / 0.92^{\mathrm{a}}$ & $0.78 / 0.75^{\mathrm{a}}$ \\
\hline Insulin secretion ${ }_{\text {OGTT }}(\mathrm{pmol} / \mathrm{mmol})$ & $304 \pm 12$ & $287 \pm 13$ & $235 \pm 19$ & $0.01 / 0.02^{\mathrm{b}}$ & $0.02 / 0.01^{\mathrm{b}}$ \\
\hline \multicolumn{6}{|l|}{ GLP-1 (pmol/l) } \\
\hline $0 \mathrm{~min}$ & $16.1 \pm 0.9$ & $17.3 \pm 1.3$ & $17.3 \pm 2.0$ & 0.91 & 0.88 \\
\hline $30 \mathrm{~min}$ & $34.1 \pm 2.1$ & $38.8 \pm 4.0$ & $38.1 \pm 3.5$ & 0.45 & 0.36 \\
\hline $120 \mathrm{~min}$ & $28.9 \pm 1.5$ & $29.0 \pm 1.7$ & $28.9 \pm 2.4$ & 0.87 & 0.88 \\
\hline Fold increase $0-30 \mathrm{~min}$ & $2.5 \pm 0.2$ & $2.7 \pm 0.3$ & $2.4 \pm 0.4$ & 0.77 & 0.84 \\
\hline
\end{tabular}

Data are means \pm SEM

$p$ values were obtained using $\chi^{2}$ test or ANOVA

Analysis for rs7901695 also revealed a significant difference in insulin secretion ( $p=0.02)$, whereas for rs7895340 and rs 11196205 no significant differences in insulin secretion were detected $(p=0.73$ and 0.76$)$

${ }^{a} p$ values were derived from multivariate linear regression models: adjusted for age, sex and BMI

${ }^{\mathrm{b}} p$ values were derived from multivariate linear regression models: adjusted for age, sex, BMI and insulin sensitivity 
Table 3 Anthropometric and metabolic data of 210 participants who underwent a combined IVGTT and hyperinsulinaemic-euglycaemic clamp

\begin{tabular}{|c|c|c|c|}
\hline \multirow[b]{2}{*}{ Genotype } & \multicolumn{2}{|l|}{ rs7903146 } & \multirow{2}{*}{$\begin{array}{l}p \text { value } \\
(\mathrm{CC} \text { vs } \mathrm{XT})\end{array}$} \\
\hline & $\mathrm{C} / \mathrm{C}$ & $\mathrm{X} / \mathrm{T}$ & \\
\hline$n$ & 97 & 113 & \\
\hline NGT/IGT & $80 / 17$ & $81 / 32$ & 0.06 \\
\hline Sex (female/male) & $59 / 38$ & $64 / 49$ & 0.58 \\
\hline Age (years) & $44 \pm 1$ & $45 \pm 1$ & 0.29 \\
\hline BMI $\left(\mathrm{kg} / \mathrm{m}^{2}\right)$ & $29.0 \pm 0.5$ & $28.8 \pm 0.5$ & 0.82 \\
\hline $\begin{array}{l}\text { Insulin sensitivity }{ }_{\text {clamp }} \\
\left(\mu \mathrm{mol} \mathrm{kg}{ }^{-1} \min ^{-1}\right. \\
\left.[\mathrm{pmol} / \mathrm{l}]^{-1}\right)\end{array}$ & $0.07 \pm 0.01$ & $0.07 \pm 0.01$ & 0.77 \\
\hline Insulin secretion index ${ }^{a}$ & & & \\
\hline $\begin{array}{l}\text { IVGTT C-peptide secretion } \\
(\mathrm{pmol} / \mathrm{l})\end{array}$ & $7,904 \pm 306$ & $7,679 \pm 323$ & 0.40 \\
\hline IVGTT insulin secretion $(\mathrm{pmol} / \mathrm{l})$ & $2,059 \pm 131$ & $1,924 \pm 129$ & 0.25 \\
\hline $\begin{array}{l}\text { OGTT insulin secretion } \\
(\mathrm{pmol} / \mathrm{mmol})\end{array}$ & $314 \pm 8$ & $292 \pm 8$ & 0.04 \\
\hline
\end{tabular}

Data are means \pm SEM

$p$ values were obtained using $\chi^{2}$ test or unpaired $t$ test or multivariate linear regression models

None of the four other SNPs in TCF7L2 (rs12255372, rs7901695, rs11196205 and rs7895340) affected significantly insulin secretion in the IVGTT (all $p>0.2$ )

${ }^{\text {a }}$ Adjusted for age, sex and BMI, and insulin sensitivity

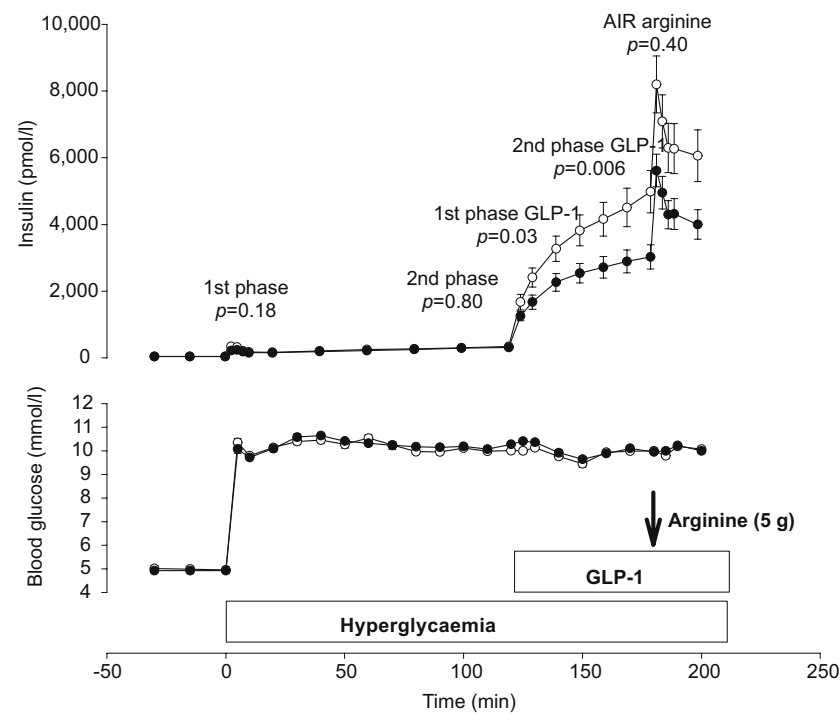

Fig. 1 Associations between the genotypes of rs7903146 polymorphism in the TCF7L2 gene with insulin secretion during a hyperglycaemic clamp in 73 German participants. Open circles CC; closed circles CT and TT. AIR Acute insulin response. Arrow Administration of $5 \mathrm{~g}$ arginine. The $p$ values show the differences for first and second phases of glucose-induced insulin secretion, first and second phases of GLP-1-induced insulin secretion and acute insulin secretory response to arginine (AIR) (for calculation see 'Methods'; insulin secretion is adjusted for insulin sensitivity)

Table 4 Anthropometric and metabolic data of 233 participants who underwent a hyperglycaemic clamp and of 73 participants who underwent a modified hyperglycaemic clamp with additional GLP-1 and arginine administration

\begin{tabular}{|c|c|c|c|c|c|c|c|c|c|}
\hline & \multicolumn{3}{|l|}{ Germany } & \multicolumn{3}{|c|}{ The Netherlands (Utrecht) } & \multicolumn{3}{|c|}{ The Netherlands (Hoorn) } \\
\hline & \multicolumn{2}{|l|}{ rs7903146 } & \multirow[t]{2}{*}{$p$ value } & \multicolumn{2}{|l|}{ rs 7903146} & \multirow[t]{2}{*}{$p$ value } & \multicolumn{2}{|l|}{ rs7903146 } & \multirow[t]{2}{*}{$p$ value } \\
\hline Genotype & $\mathrm{C} / \mathrm{C}$ & $\mathrm{X} / \mathrm{T}$ & & $\mathrm{C} / \mathrm{C}$ & $\mathrm{X} / \mathrm{T}$ & & $\mathrm{C} / \mathrm{C}$ & $\mathrm{X} / \mathrm{T}$ & \\
\hline Sex (female/male) & $15 / 20$ & $24 / 14$ & 0.08 & $5 / 31$ & $22 / 11$ & $<0.01$ & $17 / 11$ & $30 / 33$ & 0.27 \\
\hline NGT/IGT & $30 / 5$ & $27 / 11$ & 0.13 & $31 / 5$ & $26 / 7$ & 0.53 & $0 / 28$ & $0 / 66$ & - \\
\hline Age (years) & $38 \pm 2$ & $40 \pm 2$ & 0.66 & $47 \pm 1$ & $47 \pm 1$ & 0.94 & $56 \pm 1$ & $58 \pm 1$ & 0.43 \\
\hline $\operatorname{BMI}\left(\mathrm{kg} / \mathrm{m}^{2}\right)$ & $26.1 \pm 0.9$ & $25.1 \pm 0.6$ & 0.41 & $25.6 \pm 0.7$ & $26.2 \pm 0.7$ & 0.49 & $29.2 \pm 0.8$ & $27.9 \pm 0.4$ & 0.13 \\
\hline \multicolumn{10}{|l|}{ Plasma glucose $(\mathrm{mmol} / \mathrm{l})$} \\
\hline Fasting & $5.1 \pm 0.1$ & $5.0 \pm 0.1$ & 0.72 & $4.6 \pm 0.1$ & $4.8 \pm 0.1$ & 0.18 & $6.6 \pm 0.1$ & $6.6 \pm 0.1$ & 0.75 \\
\hline $2 \mathrm{~h}$ glucose & $5.9 \pm 0.3$ & $6.5 \pm 0.3$ & 0.21 & $5.7 \pm 0.3$ & $5.6 \pm 0.3$ & 0.74 & $9.5 \pm 0.1$ & $9.5 \pm 0.1$ & 0.84 \\
\hline $\begin{array}{l}\text { Insulin sensitivity }\left(\mu \mathrm{mol} \mathrm{kg}^{-1}\right. \\
\left.\min ^{-1}[\mathrm{pmol} / 1]^{-1}\right)\end{array}$ & $0.15 \pm 0.02$ & $0.15 \pm 0.01$ & 0.90 & $0.17 \pm 0.02$ & $0.18 \pm 0.02$ & 0.60 & $0.11 \pm 0.01$ & $0.14 \pm 0.01$ & 0.21 \\
\hline \multicolumn{10}{|l|}{ Insulin secretion index $(\mathrm{pmol} / \mathrm{l})^{\mathrm{a}}$} \\
\hline First phase (sum 0-10 min) & $1,067 \pm 158$ & $815 \pm 105$ & 0.18 & $963 \pm 75$ & $891 \pm 96$ & 0.76 & $699 \pm 70$ & $679 \pm 72$ & 0.68 \\
\hline Second phase & $308 \pm 47$ & $291 \pm 41$ & 0.80 & $389 \pm 42$ & $376 \pm 47$ & 0.71 & $304 \pm 45$ & $303 \pm 38$ & 0.18 \\
\hline First phase GLP-1 & $2,049 \pm 258$ & $1,466 \pm 175$ & 0.03 & n.a. & n.a. & & n.a. & n.a. & \\
\hline Second phase GLP-1 & $4,567 \pm 568$ & $2,881 \pm 341$ & 0.006 & n.a. & n.a. & & n.a. & n.a. & \\
\hline Arginine & $2,680 \pm 226$ & $2,252 \pm 181$ & 0.40 & n.a. & n.a. & & n.a. & n.a. & \\
\hline
\end{tabular}

Data are means \pm SE

$p$ values were obtained using $\chi^{2}$ test, unpaired $t$ test or multivariate linear regression models

Carriers of the risk allele for SNP rs 12255372 showed reduced first phase $(p=0.02)$ and second phase $(p=0.005)$ GLP-1-induced insulin secretion Carriers of the risk allele for SNP rs7901695 showed reduced second phase $(p=0.02)$ GLP-1-induced insulin secretion

n.a. Not available

${ }^{a}$ Adjusted for age, sex and BMI, and insulin sensitivity 


\section{Discussion}

The variants in TCF7L2 described by Grant et al. [1] that mediate an increased risk of type 2 diabetes have been found to be associated with reduced insulin secretion $[6,7,9,10]$. We could confirm this reduced insulin secretion in our study in a group of 1,110 German non-diabetic participants using Cpeptide levels during an OGTT. Unexpectedly, the i.v. application of glucose during an IVGTT did not affect insulin secretion in carriers of the risk alleles for SNPs in TCF7L2. The same results were obtained using i.v. glucose challenge during a hyperglycaemic clamp in subgroups of the German population and a population from the Netherlands. The observed different results between an orally and i.v. administered glucose challenge generate the hypothesis that incretininduced insulin secretion is affected by the variants in the TCF7L2 gene. Possible mechanisms explaining these findings include impaired incretin production or incretin signalling.

To address this issue we first measured basal GLP-1 concentrations and GLP-1 response during an OGTT. None of the tested variants that have been shown in the literature to exert a reproducible effect on type 2 diabetes were associated with basal GLP-1 levels or with GLP-1 response during the OGTT.

Furthermore, we combined the hyperglycaemic clamp with additional GLP-1 infusion to measure GLP-1-induced insulin secretion. Both acute (so called first phase) and prolonged (so called second phase) GLP-1-induced insulin secretion during the hyperglycaemic clamp were significantly impaired in carriers of the risk alleles in TCF7L2. These data suggest that participants carrying the risk alleles have an impaired insulin secretion due to an impairment of the GLP-1 signalling chain.

The putative molecular mechanism for this finding is not clear. As the transcription factor TCF7L2 plays an essential role in the WNT signalling pathway [14], which on the one hand is required for a normal development of the pancreas and the pancreatic islets [26] and on the other hand is crucial for the regulation of GLP-1 expression and secretion in intestinal L cells [14]. In theory, polymorphisms in the TCF7L2 gene might therefore through alteration of the WNT signalling pathway directly affect beta cell growth, beta cell differentiation and beta cell function. Furthermore insulin secretion might also be affected indirectly via the enteroinsular axis either through an impaired overall GLP-1 secretion or through a defective or dysfunctional GLP-1induced insulin secretion. An impaired or dysfunctional GLP-1 effect might result first in a reduced postprandial insulin secretion and second, might influence stimulation of beta cell growth and beta cell differentiation.

Our data show that basal and glucose-induced GLP-1 secretion during the OGTT were not affected by any of the analysed SNPs, whereas the first and second phases of
GLP-1-induced insulin secretion were significantly reduced in carriers of the risk alleles in three of the five abovedescribed SNPs in the TCF7L2 gene, among them rs7903146, which is most strongly associated in the literature with type 2 diabetes $[1,6,9,12,13]$. The finding that basal and glucose-stimulated GLP-1 secretion were not influenced by the TCF7L2 polymorphisms indicates that a reduced GLP-1 secretion is not likely to explain the impaired insulin secretion in carriers of the risk genotypes, although it can not fully exclude an effect of these SNPs on GLP-1 levels. First, by measuring total GLP-1 levels, we may have missed a subtle defect in GLP-1 secretion, which may have been detected by measuring the active form of GLP-1. Second, systemic GLP-1 levels may not adequately reflect the level of the active hormone acting in the gut wall on the autonomic nervous system [27]. Third, impaired TCF7L2 activity might tissue-specifically reduce the GLP-1 levels in the brain, which are believed as well to be important for insulin secretion [28].

While we have no evidence for reduced GLP-1 secretion we have strong evidence for an impaired GLP-1-induced insulin secretion in carriers of the above-described polymorphisms in TCF7L2. The data show a reduced efficiency of GLP-1 to stimulate insulin secretion in pancreatic beta cells. Alterations of the GLP-1 signalling pathway in beta cells might thereby play a role. Recently the TCF7L2 gene was also identified in human pancreas [14]. Therefore variations in this transcription factor could specifically impair the transcription of genes involved in the incretin signalling chain, resulting in resistance of the pancreatic beta cells to GLP-1.

In contrast to the observed reduction in the first and second phases of GLP-1-induced insulin secretion, the arginineinduced insulin secretion was not significantly affected by the analysed SNPs in the TCF7L2 gene. The arginine bolus in the combined hyperglycaemic clamp produces a maximal challenge for the secretory capacity of the beta cell and can be considered as a surrogate for beta cell mass $[15,20]$. The SNPs do not affect this maximal insulin secretion, suggesting that the variants in $T C F 7 L 2$ do not influence beta cell mass, at least in the prediabetic state. In addition, impaired beta cell function may also include the efficiency of the conversion from proinsulin to insulin [21]. However, there was no evidence for this abnormality related to the variants in the TCF7L2 gene during the hyperglycaemic clamp (data not shown).

We also found that insulin sensitivity calculated from the OGTT using an established index [25] was significantly increased in participants carrying the risk alleles for all analysed SNPs in the TCF7L2 gene. This was also described in the study of Florez et al. [9]. When we measured insulin sensitivity with the gold standard, the euglycaemic-hyperinsulinaemic clamp and the hypergly- 
caemic-hyperinsulinaemic clamp, we found no association of the risk alleles with insulin sensitivity. Taken together, our data suggest that the variants in the TCF7L2 gene do not have a strong effect on insulin sensitivity.

In summary, our data show that variations in the TCF7L2 gene are associated with impaired GLP-1-induced insulin secretion. This might be consistent with a state of relative incretin resistance. Increasing the incretin levels by pharmacological tools may thus be a logical therapy to overcome impaired insulin secretion in carriers of the TCF $7 L 2$ variants.

Acknowledgements We thank all the research volunteers for their participation. We gratefully acknowledge the superb technical assistance of A. Bury, H. Luz and L. Bagger. The studies were supported by grants from the Deutsche Forschungsgemeinschaft (KFO 114, Ga 386/9-1), the European Community's FP6 EUGENE2 (LSHM-CT2004-512013), Merck Sharp \& Dohme, the Netherlands Organisation for Health Research and Development, the RIDE programme, the Center for Medical Systems Biology (CMSB) and the Diabetes Research Foundation Amersfoort, the Netherlands.

Duality of interest The authors declare that there is no duality of interest associated with this manuscript.

\section{References}

1. Grant SF, Thorleifsson G, Reynisdottir et al (2006) Variant of transcription factor 7-like 2 (TCF7L2) gene confers risk of type 2 diabetes. Nat Genet 38:320-323

2. Stumvoll M, Haring H (2002) The peroxisome proliferatoractivated receptor-gamma2 Pro12Ala polymorphism. Diabetes 51:2341-2347

3. Schwanstecher C, Schwanstecher M (2002) Nucleotide sensitivity of pancreatic ATP-sensitive potassium channels and type 2 diabetes. Diabetes 51(Suppl 3):S358-S362

4. Chandak GR, Janipalli CS, Bhaskar et al (2006) Common variants in the TCF7L2 gene are strongly associated with type 2 diabetes mellitus in the Indian population. Diabetologia 50:63-67

5. Vliet-Ostaptchouk JV, Shiri-Sverdlov R, Zhernakova et al (2006) Association of variants of transcription factor 7-like 2 (TCF7L2) with susceptibility to type 2 diabetes in the Dutch Breda cohort. Diabetologia 50:59-62

6. Saxena R, Gianniny L, Burtt et al (2006) Common single nucleotide polymorphisms in $T C F 7 L 2$ are reproducibly associated with type 2 diabetes and reduce the insulin response to glucose in nondiabetic individuals. Diabetes 55:2890-2895

7. Damcott CM, Pollin TI, Reinhart et al (2006) Polymorphisms in the transcription factor 7-like 2 (TCF7L2) gene are associated with type 2 diabetes in the Amish: replication and evidence for a role in both insulin secretion and insulin resistance. Diabetes 55:2654-2659

8. Zhang C, Qi L, Hunter DJ et al (2006) Variant of transcription factor 7-like 2 (TCF7L2) gene and the risk of type 2 diabetes in large cohorts of U.S. women and men. Diabetes 55: 2645-2648

9. Florez JC, Jablonski KA, Bayley $\mathrm{N}$ et al (2006) TCF7L2 polymorphisms and progression to diabetes in the Diabetes Prevention Program. N Engl J Med 355:241-250

10. Scott LJ, Bonnycastle LL, Willer CJ et al (2006) Association of transcription factor 7-like 2 (TCF7L2) variants with type 2 diabetes in a Finnish sample. Diabetes 55:2649-2653
11. Reynisdottir I, Thorleifsson G, Benediktsson R et al (2003) Localization of a susceptibility gene for type 2 diabetes to chromosome 5q34-q35.2. Am J Hum Genet 73:323-335

12. Cauchi S, Meyre D, Dina C et al (2006) Transcription factor $T C F 7 L 2$ genetic study in the French population: expression in human beta-cells and adipose tissue and strong association with type 2 diabetes. Diabetes 55:2903-2908

13. Helgason A, Palsson S, Thorleifsson G et al (2007) Refining the impact of TCF7L2 gene variants on type 2 diabetes and adaptive evolution. Nat Genet 39:218-225

14. Yi F, Brubaker PL, Jin T (2005) TCF-4 mediates cell typespecific regulation of proglucagon gene expression by $\beta$ catenin and glycogen synthase kinase-3 $\beta$. J Biol Chem 280: f1457-1464

15. Fritsche A, Stefan N, Hardt E, Schutzenauer S, Haring H, Stumvoll M (2000) A novel hyperglycaemic clamp for characterization of islet function in humans: assessment of three different secretagogues, maximal insulin response and reproducibility. Eur J Clin Investig 30:411-418

16. Tripathy D, Wessman Y, Gullstrom M, Tuomi T, Groop L (2003) Importance of obtaining independent measures of insulin secretion and insulin sensitivity during the same test: results with the Botnia clamp. Diabetes Care 26:1395-1401

17. 't Hart LM, Fritsche A, Rietveld I et al (2004) Genetic factors and insulin secretion: gene variants in the IGF genes. Diabetes 53 (Suppl 1):S26-S30

18. Ruige JB, Dekker JM, Nijpels G et al (1999) Hyperproinsulinaemia in impaired glucose tolerance is associated with a delayed insulin response to glucose. Diabetologia 42:177-180

19. van Haeften TW, Dubbeldam S, Zonderland ML, Erkelens DW (1998) Insulin secretion in normal glucose-tolerant relatives of type 2 diabetic subjects. Assessments using hyperglycemic glucose clamps and oral glucose tolerance tests. Diabetes Care 21:278-282

20. Fritsche A, Stefan N, Hardt E, Haring H, Stumvoll M (2000) Characterisation of beta-cell dysfunction of impaired glucose tolerance: evidence for impairment of incretin-induced insulin secretion. Diabetologia 43:852-858

21. Stumvoll M, Fritsche A, Madaus et al (2001) Functional significance of the UCSNP-43 polymorphism in the CAPN10 gene for proinsulin processing and insulin secretion in nondiabetic Germans. Diabetes 50:2161-2163

22. Tschritter O, Stumvoll M, Machicao et al (2002) The prevalent Glu23Lys polymorphism in the potassium inward rectifier 6.2 (KIR6.2) gene is associated with impaired glucagon suppression in response to hyperglycemia. Diabetes 51:2854-2860

23. Olivier M, Chuang LM, Chang MS et al (2002) High-throughput genotyping of single nucleotide polymorphisms using new biplex invader technology. Nucleic Acids Res 30:e53

24. Deacon CF, Johnsen AH, Holst JJ (1995) Degradation of glucagon-like peptide-1 by human plasma in vitro yields an Nterminally truncated peptide that is a major endogenous metabolite in vivo. J Clin Endocrinol Metab 80:952-957

25. Matsuda M, DeFronzo RA (1999) Insulin sensitivity indices obtained from oral glucose tolerance testing: comparison with the euglycemic insulin clamp. Diabetes Care 22:1462-1470

26. Papadopoulou S, Edlund H (2005) Attenuated Wnt signaling perturbs pancreatic growth but not pancreatic function. Diabetes $54: 2844-2851$

27. Hansen L, Deacon CF, Orskov C, Holst JJ (1999) Glucagon-like peptide-1-(7-36)amide is transformed to glucagon-like peptide-1(9-36)amide by dipeptidyl peptidase IV in the capillaries supplying the L cells of the porcine intestine. Endocrinology 140:5356-5363

28. D'Alessio DA, Sandoval DA, Seeley RJ (2005) New ways in which GLP-1 can regulate glucose homeostasis. J Clin Invest $115: 3406-3408$ 